\title{
Dosing of Erythropoiesis-Stimulating Agents Can Be Reduced by a New Administration Regimen
}

\author{
Bergur V. Stefánsson Börje Haraldsson Ulf Nilsson
}

Department of Molecular and Clinical Medicine-Nephrology, Institute of Medicine, Sahlgrenska Academy, University of Gothenburg, Gothenburg, Sweden

\section{Key Words}

Anemia $\cdot$ Chronic renal failure $\cdot$ Erythropoietin responsiveness $\cdot$ Erythropoietin-stimulating agents $\cdot$ Hemodialysis $\cdot$ Renal anemia

\begin{abstract}
Background/Aims: At our hemodialysis (HD) unit, we noted a drop in the treatment dose of erythropoietin-stimulating agents (ESAs) when the frequency of dose adjustment was reduced from weekly, where doses were withheld if hemoglobin was $>130 \mathrm{~g} / \mathrm{l}$, to monthly, where doses were not withheld. The aim of this study was to find an explanation for this reduction in ESA requirement. Methods: This is a retrospective study on 18 stable HD patients. Comparable follow-up periods of 6 months with the two different ESA adjustment regimens were established and data on ESA dose, hemoglobin and known predictors of ESA response were collected. Results: With the new ESA administration regimen, a 22.5\% drop in the total ESA dose was noted. The corresponding fall in the erythropoietin resistance index was $20.0 \%$. Simultaneously, the dialysis dose and transferrin saturation increased significantly. However, in a multivariate linear regression model, changes in these factors did not significantly predict changes in ESA requirement. No relevant changes were noted in other erythropoiesis-modulating factors. Conclusion: Frequent dose adjustments and the current ESA administration practice of withholding ESA doses does not seem to reduce ESA demand. On the contrary, such practice is likely to increase ESA requirement over time.

Copyright $\odot 2011$ S. Karger AG, Basel
\end{abstract}




\section{Introduction}

In chronic renal failure, anemia is generally believed to result from insufficient production of erythropoietin by the diseased kidneys [1]. However, the etiology is much more complex: many anemic patients have serum erythropoietin levels within the reference interval $[2,3]$ and numerous factors can affect erythropoiesis, such as iron deficiency, inflammation, infection, uremic toxins, malnutrition and hyperparathyroidism [4].

The core treatment of renal anemia is to stimulate erythropoiesis by regular injections with erythropoiesis-stimulating agents (ESAs), such as recombinant human erythropoietin [5]. This treatment is expensive and constitutes a substantial part of the dialysis patients' total health care costs [6]. According to international guidelines, the optimal hemoglobin level in patients with end-stage renal disease is $110-120 \mathrm{~g} / 1[5,7]$. It is not easy to maintain hemoglobin within these tight limits, and ESA doses are adjusted frequently.

In our hemodialysis (HD) unit, hemoglobin levels have been measured weekly for many years and the ESA dose was withheld if the hemoglobin value was $>130 \mathrm{~g} / \mathrm{l}$. On the basis of the observed large fluctuations in week-to-week hemoglobin values as well as the possibility of neocytolysis [8] and erythroid progenitor apoptosis when ESA treatment is withdrawn [9], we decided to change this practice. From November 1, 2007, hemoglobin measurements and ESA dose adjustments were performed monthly instead of weekly. Moreover, the ESA dose was withheld only if the hemoglobin value was $>140 \mathrm{~g} / \mathrm{l}$. After this change in ESA administration, we experienced an approximately $20 \%$ reduction in the total ESA supplementation. The aim of this study was to evaluate if the change in the ESA administration practice could explain the reduction in the ESA demand.

\section{Patients and Methods}

\section{Patients and Study Design}

We conducted a retrospective analysis on data from our Renal Unit at the Sahlgrenska University Hospital, Mölndal, Sweden. The main demographic and clinical characteristics of the study subjects are summarized in table 1.

Figure 1 shows an algorithm denoting the screening and inclusion/exclusion details. All patients on chronic HD treatment on November 1, 2007, were screened for participation in the study. At this date, our routines regarding the administration of ESA were changed (change point). Patients meeting the inclusion criteria had been on HD for at least 3 months prior to the study start. They were also treated regularly with subcutaneous ESA injections. Among eligible subjects, we carefully selected patients to create a subpopulation allowing analysis of intra-individual changes in ESA requirement. For each patient, comparable periods of equal duration ( 6 months) before and after the change point were selected (periods 1 and 2, respectively).

The patients had to be in clinically stable condition and were excluded if any of the following criteria occurred within 8 months before or within 7 months after the change point; acute inflammation/infection with C-reactive protein (CRP) $>150 \mathrm{mg} / \mathrm{l}$ at any time or CRP $>100 \mathrm{mg} / \mathrm{l}$ for $>2$ days, acute operation, blood transfusion, acute cardiovascular event (acute myocardial infarction or stroke) or diagnosis of cancer. Moreover, we excluded patients if the rate of HD per week was higher after the change point. After applying the exclusion criteria, data from 18 patients were collected and analyzed. 
Fig. 1. Screening and inclusion/ exclusion details of all patients on chronic hemodialysis (HD) on November 1, 2007, for participation in the study. At this date, our routines regarding ESA administration were changed (change point). Patients meeting the inclusion criteria had been on hemodialysis for at least 3 months prior to the study start.

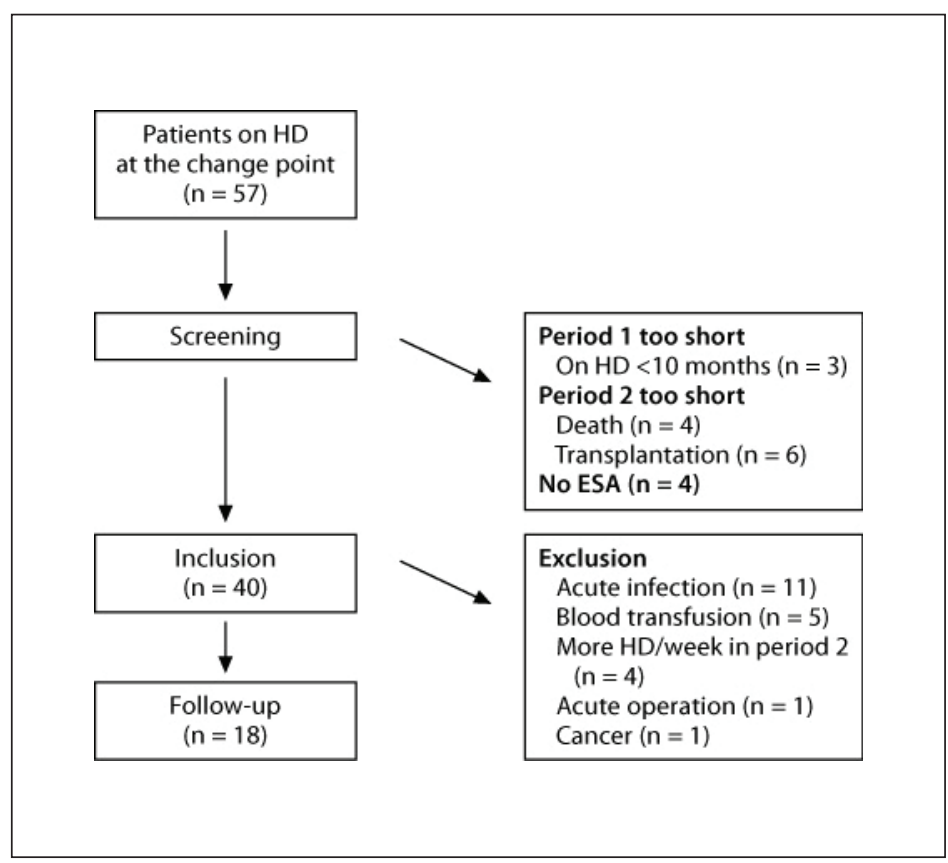

Table 1. The main demographic and clinical characteristics of the study subjects

\begin{tabular}{lc}
\hline Patients, $\mathrm{n}$ & 18 \\
$\quad$ Females/males & $7 / 11$ \\
Age, years & $66.6 \pm 12.5$ \\
Causes of renal failure, $\mathrm{n}$ & \\
$\quad$ Unknown & 6 \\
$\quad$ Diabetic nephropathy & 4 \\
Chronic glomerulonephritis & 1 \\
$\quad$ Chronic interstitial nephritis & 3 \\
$\quad$ Nephrosclerosis & 1 \\
$\quad$ Other & 3 \\
Time on current HD treatment, months & $41.1 \pm 32.1$ \\
Dry weight, $\mathrm{kg}$ & $77.7 \pm 15.5$ \\
Serum levels & $773 \pm 182$ \\
$\quad$ Creatinine, $\mu \mathrm{mol} / \mathrm{l}$ & $24.6 \pm 6.2$ \\
$\quad$ Urea, mmol/l & $2.23 \pm 0.11$ \\
Calcium, $\mathrm{mmol} / \mathrm{l}$ & $1.8 \pm 0.5$ \\
Phosphate, $\mathrm{mmol} / \mathrm{l}$ & $22.9 \pm 1.3$ \\
$\quad$ Bicarbonate, $\mathrm{mmol} / \mathrm{l}$ & \\
\hline
\end{tabular}

\section{Change in the ESA Administration Regimen}

On November 1, 2007, we changed our erythropoietin administration regimen. Before that day, hemoglobin measurements and ESA dose adjustments were performed weekly. Capillary hemoglobin was measured before dialysis and if it was $>130 \mathrm{~g} / \mathrm{l}$ the dialysis nurse automatically withheld the ESA dose. The following week, ESA was restarted with a lower dose if the hemoglobin value had dropped $<120 \mathrm{~g} / \mathrm{l}$; otherwise it was withheld for another week. Subsequently, we changed this practice. For all patients, the prescription of ESA was altered. The new dose was based on the previous mean delivered ESA dose over time, calcu- 
lated as total ESA dose administered per week for the previous 12 months or from the start of dialysis. In all cases, this dose was lower than the prescribed one because of the 'withholddose' practice. No capillary hemoglobin measurements were performed, and the ESA dose was instead adjusted to monthly hemoglobin measurements performed at our local clinical laboratory. The dose was adjusted if hemoglobin was $>120$ or $<110 \mathrm{~g} / \mathrm{l}$, and the dose was only withheld if hemoglobin exceeded $140 \mathrm{~g} / \mathrm{l}$. In all cases, ESA dose adjustments were performed according to the physicians' judgment.

\section{Dialysis Treatment and Blood Sampling}

For each patient, the dialysis modality was the same in both periods. No patient was treated with hemodiafiltration or hemofiltration. At the change point, the method applied to measure the dialysis dose was changed from single-pool Kt/V (spKt/V), with urea measured 2 min after dialysis, to equilibrated $\mathrm{Kt} / \mathrm{V}(\mathrm{eKt} / \mathrm{V})$ with urea measured immediately after dialysis [10]. As these two methods do not give comparable results, dialysis dose was calculated as dialyzed blood volume per kilogram per dialysis session. Arteriovenous (AV) fistula recirculation was evaluated every month using Transonic flow surveillance.

At the change point, we also altered our practice regarding monthly blood sample collection. Blood was now collected before the start of the midweek dialysis session (2 days after the previous dialysis) instead of the first dialysis session in the week (3 days after). All the above-described changes were done to adapt our routines to international guidelines [11] and the National Hemodialysis Cross-Sectional Study performed twice a year throughout the country by the Swedish Dialysis Data Base.

\section{Data Collection, Calculations and Statistical Analyses}

The original intention was to collect data from each patient for 12 months in each period. However, only 10 patients were stable and eligible for the study over such a long time. Instead, data from 6 months in each period were collected. As the ESA dose was fixed during the 1st month after the change point, this month, as well as the month before the change point was excluded.

Monthly routine clinical laboratory analyses from our local dialysis database were collected. From the same database, information of potential blood transfusions, dialysis dose and iron/erythropoietin supplementation were assessed.

The time point for monthly blood collection was changed between periods 1 and 2, but this was compensated for by calculating a corrected hemoglobin value after dialysis from the linear relationship between the hemoglobin value before dialysis and the respective intradialytic body weight loss [12]. Thus, hemoglobin values in periods 1 and 2 were rendered comparable and these values were then used to calculate the erythropoietin resistance index (ERI): ERI = ESA dose (IU/week)/weight $(\mathrm{kg}) /$ hemoglobin value $(\mathrm{g} / \mathrm{dl})$, where IU is the abbreviation for international units.

Microsoft Excel software was used to register data and generate graphs. Data are presented as means or medians \pm SD. Statistical analyses were performed with the software package SPSS. Because of the small study cohort, non-parametric tests (Wilcoxon and Kruskal-Wallis tests) were regarded as appropriate to compare means. Spearman's correlation ( $\rho$ ) was used to study bivariate associations, and a univariate linear regression model was used in multiple regression analyses. 


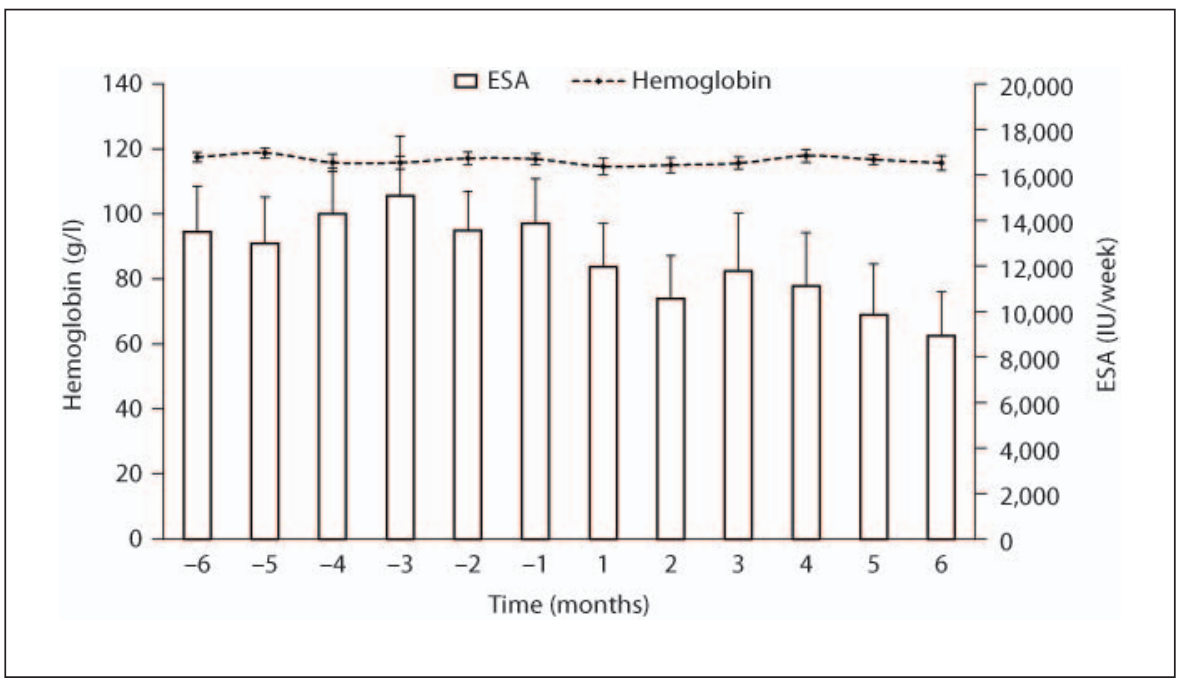

Fig. 2. Month-to-month variation in total ESA supplementation per week and hemoglobin levels before dialysis during the entire follow-up.

\section{Results}

\section{Hemoglobin, ESA Supplementation and ESA Resistance}

Sixteen patients received weekly subcutaneous epoetin $\beta$ injections (NeoRecormon ${ }^{\circledR}$; Roche) and 2 patients were treated with intravenous darbepoetin $\alpha$ (Aranesp ${ }^{\circledR}$; Amgen) every other week. Both of these patients were switched to epoetin $\beta$ during period 2 . The dose of darbepoetin $\alpha$ was multiplied with 200 to convert from micrograms into IU.

Figure 2 illustrates month-to-month variation in total ESA supplementation per week and hemoglobin levels before dialysis during the entire follow-up time. The range of ESA doses prescribed was 4,000-30,000 IU per week in period 1 and 2,000-30,000 IU per week in period 2. The mean ESA dose levels, the ERI and hemoglobin values during the respective periods are shown in table 2. The magnitudes of all these parameters were lower in period 2, albeit being only significant for ESA dose and ERI. The reduction was $22.5 \%$ for the mean ESA dose per week, $19.9 \%$ for ERI, $0.9 \%$ for hemoglobin before and $1.9 \%$ for hemoglobin after dialysis. The mean reductions in the ESA dose per week and ERI were $-4,015 \pm 3,633 \mathrm{IU}$ and $-3.0 \pm 4.3 \mathrm{IU} /$ week per $\mathrm{kg}$ per $\mathrm{g} / \mathrm{dl}$, respectively.

\section{Predictors of ESA Response}

Table 3 shows mean levels of well-known predictors of ESA response in each period. Serum transferrin saturation and dialyzed blood volume were significantly increased in period 2. Further, together with serum ferritin, these parameters were significantly negatively correlated to changes in ERI (table 4). However, in an adjusted model where serum ferritin and transferrin saturation were omitted due to bidirectional effects with the outcome variable, dialysis dose was not a significant independent predictor of change in ERI (table 5). The mean dialysis dose measured by Kt/V was $1.46 \pm 0.23(\mathrm{spKt} / \mathrm{V})$ in period 1 and $1.41 \pm 0.21(\mathrm{eKt} / \mathrm{V})$ in period 2. No further statistical analyses were performed as these two parameters are not equivalent. In patients with an AV fistula, no recirculation was observed during the follow-up.

There was a significant difference between periods 1 and 2 regarding the time that had passed from intravenous iron injection to the analysis of iron parameters. Thus, in period 1 , 64 of 108 blood samples were collected within 3 weeks (mean 10.3 days), compared to 70 of 
Table 2. Erythropoiesis parameters during both periods (means $\pm \mathrm{SD}$ )

\begin{tabular}{lccc}
\hline Parameters & Period 1 & Period 2 & p value \\
\hline Hemoglobin, g/l & & & \\
$\quad$ Before dialysis & $117.0 \pm 4.8$ & $115.9 \pm 5.1$ & $\mathrm{NS}$ \\
$\quad$ After dialysis & $125.1 \pm 4.7$ & $122.7 \pm 5.4$ & $\mathrm{NS}$ \\
Intravenous iron treatment, mg/day & $5.1 \pm 4.5$ & $5.0 \pm 3.9$ & $\mathrm{NS}$ \\
ESA dose, IU/kg/week & $186.5 \pm 117.8$ & $144.6 \pm 126.4$ & $<0.01$ \\
ERI, IU/kg/week per g/dl & $15.1 \pm 9.9$ & $12.1 \pm 11.0$ & $<0.01$ \\
\hline
\end{tabular}

${ }^{a}$ Estimated hemoglobin according to Bellizzi et al. [12].

Table 3. Mean levels of well-known predictors of ESA response in both periods (means \pm SD)

\begin{tabular}{lccc}
\hline Predictors & Period 1 & Period 2 & p value \\
\hline Dialysis sessions, $\mathrm{n}$ & $76.8 \pm 2.7$ & $75.9 \pm 6.4$ & $\mathrm{NS}$ \\
Dialyzed blood volume, $1 / \mathrm{kg} /$ session & $0.90 \pm 0.20$ & $0.98 \pm 0.18$ & $<0.01$ \\
Serum transferrin saturation, \% & $22.2 \pm 5.1$ & $27.6 \pm 9.4$ & $<0.05$ \\
Serum ferritin, $\mu \mathrm{g} / \mathrm{l}$ & $470 \pm 189$ & $528 \pm 243$ & $\mathrm{NS}$ \\
Serum CRP, $\mathrm{mg} / \mathrm{l}$ & $9.9 \pm 7.2$ & $12.6 \pm 11.1$ & $\mathrm{NS}$ \\
Serum albumin, g/l & $35.8 \pm 2.2$ & $36.2 \pm 3.5$ & $\mathrm{NS}$ \\
Serum PTH, ng/l & $419 \pm 384$ & $353 \pm 210$ & $\mathrm{NS}$ \\
\hline
\end{tabular}

Table 4. Spearman's correlation ( $\rho$ ) between changes in predictors of erythropoiesis and changes in ERI

Table 5. Results of a multiple linear regression model with ERI as outcome and changes in factors influencing erythropoiesis as predictors

\begin{tabular}{lrl}
\hline Predictors & $\mathrm{r}_{\mathrm{s}}$ & $\mathrm{p}$ value \\
\hline Changes in & & \\
$\quad$ Dialyzed blood volume & -0.55 & 0.017 \\
Serum transferrin saturation & -0.55 & 0.018 \\
Serum ferritin & -0.48 & 0.042 \\
Serum CRP & 0.44 & 0.065 \\
Serum albumin & 0.00 & 1.000 \\
Serum PTH & -0.19 & 0.453 \\
\hline
\end{tabular}

\begin{tabular}{lrrr}
\hline Predictors & $\beta$ & \multicolumn{1}{c}{$95 \%$ CI } & p value \\
\hline Changes in & & & \\
$\quad$ Dialyzed blood & & & \\
$\quad$ volume & -17.44 & -40.71 to 5.84 & 0.130 \\
Serum CRP & 0.037 & -0.34 to 0.42 & 0.838 \\
Serum albumin & 0.015 & -1.13 to 1.16 & 0.979 \\
Serum PTH & 0.001 & -0.01 to 0.01 & 0.712 \\
\hline
\end{tabular}

Transferrin saturation and ferritin were omitted from the model because they are modified by ESA. 
107 (mean 6.9 days) in period 2 ( $\mathrm{p}<0.001)$. Further, in period 1, all samples were collected $>3$ days after the intravenous iron injection, while in period 2, 26 samples were drawn within 3 days ( 6 patients). In these 6 patients, serum ferritin and transferrin saturation increased significantly in period $2(+224 \pm 89 \mu \mathrm{g} / \mathrm{l}$ and $+12.3 \pm 6.1 \%$, respectively; $\mathrm{p}=0.028$ in both cases). On the other hand, this was not seen in the other 12 patients where all samples were collected $>3$ days after intravenous iron injection. Here, the changes from period 1 to period 2 in serum ferritin levels and serum transferrin saturation were $-25.4 \pm 281 \mu \mathrm{g} / \mathrm{l}$ and $+1.9 \pm 8.0 \%$, respectively (nonsignificant).

Sixteen patients were treated with intravenous iron injections, 2 of them only in period 1 and 2 patients only in period 2. Mostly iron sucrose (Venofer ${ }^{\circledR} ; 100 \mathrm{mg} /$ injection) was used in period 1 (157/169 doses) while iron dextran (Cosmofer ${ }^{\circledR} ; 50$ or $100 \mathrm{mg}$ /injection) was more frequently used in period 2 (115/174 doses). The total intravenous iron supplementation did not differ between periods 1 and 2 (16.7 and $16.5 \mathrm{~g}$, respectively). To analyze the possible relationship between changes in iron dose and changes in ERI, we divided the patients into two groups: A (more intravenous iron in period $2, \mathrm{n}=6$ ) and $\mathrm{B}$ (less or equal intravenous iron in period $2, \mathrm{n}=12)$. The reduction in ERI was larger in group B than in group A $(-3.4 \pm 3.1 \mathrm{vs}$. $-2.1 \pm 6.4 \mathrm{IU} /$ week $/ \mathrm{kg}$ per $\mathrm{g} / \mathrm{dl}$, respectively). However, this difference was not statistically significant $(\mathrm{p}=0.553)$.

At the start of follow-up, 7 patients had an AV fistula and 11 had permanent central dialysis catheters (CDK). During the follow-up, 6 patients had their dialysis access changed from CDK to AV fistula. The mean $\triangle \mathrm{ERI}$ for these 6 patients was $-4.5 \pm 3.7$, compared to $-0.6 \pm 4.0$ and $-4.6 \pm 4.6$ for patients with AV fistula and CDK, respectively. The difference between the groups was not statistically significant.

\section{Predictors of Hemoglobin Concentration}

In a bivariate Spearman's correlation analysis $(\rho)$, changes in transferrin saturation and serum ferritin were significantly correlated with changes in hemoglobin after dialysis $(\mathrm{p}=$ 0.02 and 0.04 ), while changes in ESA dose per week were not significant. In a multiple regression analysis, with changes in hemoglobin after dialysis as outcome and changes in transferrin saturation, dialyzed blood volume, CRP, serum albumin and parathyroid hormone $(\mathrm{PTH})$ as predictors, only transferrin saturation turned out as an independent predictor $(\beta=0.414, p=0.019)$.

\section{Discussion}

The aim of this retrospective study was to find out if it is a reasonable assumption that a new ESA administration regimen with fewer dose adjustments and fewer withheld doses could explain a $22 \%$ drop in total ESA supplementation. Such an assumption can only be made by ruling out other possible explanations, such as changes in factors that are known to affect erythropoiesis. We systematically evaluated these factors and found two other potential explanations; increased dialysis dose and higher transferrin saturation. However, as discussed below, in our opinion, the drop in ESA requirement is most likely due to the new ESA administration routine.

In patients with chronic renal failure, the hematocrit response to ESA is dose dependent [13] but dose variation is huge, both between individuals [14] and within a given individual [15]. In consequence, frequent dose adjustments are required to keep the hemoglobin value within the recommended interval [16], i.e. between 110 and $120 \mathrm{~g} / \mathrm{l}$ in patients on chronic HD $[5,7]$. In our study, the mean hemoglobin level before dialysis was within this range and ESA requirement was comparable to that reported by others [17]. 
Numerous factors can affect the ESA response [4], e.g. inflammation and infection [18, 19], iron deficiency [20], malnutrition [21] and dialysis dose [22]. This study was designed to minimize the influence of these factors by creating comparable individual study periods before and after the change point. Periods with severe acute infection or inflammation were excluded. However, the mean serum CRP level was higher in period 2, although the difference was not significant. In fact, this excludes this factor as explanation for lower ERI in period 2. All patients were iron replete and, as the overall iron supplementation was similar in both periods, we can reject intravenous iron treatment as explanation for the decrease in ESA requirement. However, surprisingly, serum transferrin saturation was significantly higher in period 2. If true, this could explain a lower ERI, because changes in transferrin saturation predicted changes in hemoglobin. Therefore, what is the explanation for the enhanced saturation? Most likely, it is due to the shorter interval between intravenous iron injection and measurement of iron parameters in period 2, but other reasons are also possible. In period 2 , more patients were treated with iron dextran and, as it has a longer half-life [23] than iron sucrose, the intravenous iron agent mainly used in period 1, this may explain the longerlasting elevation in serum iron parameters after the injection. Further, withholding ESA doses in period 1 can affect iron homeostasis in various ways through factors like neocytolysis (see below), iron utilization and hepcidin.

The changes in serum ferritin were not correlated to the changes in CRP, indicating that the rise in ferritin did not reflect inflammation. Not surprisingly, changes in ferritin were negatively related to changes in ERI (table 4), a finding simply reflecting higher iron utilization when ESA dose is increased.

Serum albumin is a strong predictor of ERI [24] and a marker of inflammation [25] and malnutrition [26]. The albumin level was slightly, but not significantly, higher in period 2. On the other hand, changes in albumin were not correlated to changes in ERI (table 4), which speaks against an improved nutritional status as part of the explanation.

An inverse correlation has been described between the adequacy of dialysis (measured by $\mathrm{Kt} / \mathrm{V}$ ) and changes in ERI [22]. Unfortunately, the change from spKt/V to eKt/V at the change point made comparison of this parameter impossible. Instead, the dialysis dose was measured by dialyzed blood volume per kg body weight per dialysis session. As demonstrated in table 4 , a change in dialysis dose was negatively correlated with changes in ERI, but it was not a significant independent predictor of ERI in a multiple regression model (table 5). However, there is a possibility of a type- 2 error here, as the confidence interval for $\beta$ was wide and predominantly negative. In this case, an increase in the dialysis dose could explain a decrease in ESA need. If true, this is in contrast to previous studies in patients on HD thrice weekly, reporting that the beneficial effect of dialysis dose on erythropoiesis vanishes at $\mathrm{Kt} / \mathrm{V}>1.3[27,28]$.

Concomitant with the change in ESA administration practice, the monthly blood collection was rescheduled from the 1st to the 2nd dialysis session in the week [12]. In theory, HD patients without adequate urine production gain less weight with shorter inter-dialysis periods which results in higher hemoglobin values and, consequently, downward adjustment of the ESA dose. Indeed, this could be part of the explanation for the decreased ESA use in period 2. Arguing against this is that we did not note any increase in hemoglobin before dialysis after the change point. On the contrary, the mean hemoglobin value before dialysis was lower in the month succeeding $(116.6 \pm 7.6 \mathrm{~g} / \mathrm{l})$ than in the month preceding the change point $(118.4 \pm 8.9 ; \mathrm{p}=0.285)$.

One could argue that the reduced ESA demand is explained simply by the fall in the hemoglobin value. Indeed, simultaneously with the drop in ESA dose by 4,015 IU per week, hemoglobin levels before and after HD fell by 1.1 and $2.4 \mathrm{~g} / \mathrm{l}$ respectively. However, changes in hemoglobin were not correlated to changes in ESA dose. 
Taken together, the reason for the lower ESA requirement after the change point is not clear. For many years, we believed that we could reduce ESA costs by withholding doses if the hemoglobin value was $>130 \mathrm{~g} / \mathrm{l}$. There is a possibility of neocytolysis when ESA doses are withheld. This is a normal physiological mechanism where the body rapidly adapts to inappropriately high levels of red cell mass by promptly decreasing the erythropoietin production [29]. In turn, young erythrocytes are rapidly removed from the circulation by hemolysis in the spleen. Indeed, it has been postulated that neocytolysis can contribute to anemia in HD patients when EPO doses are withheld [8]. There is another potential consequence of withholding the ESA dose in an ESA-dependent patient: As erythropoietin prevents apoptotic death of erythroid precursor cells [30,31], a sudden drop in erythropoietin concentration can result in a more pronounced loss of these cells.

The major limitation of this study is that it is small and observational. Optimally, our results should be confirmed by prospective randomized trials that can give us answers to the following questions evoked by our work: Does neocytolysis occur when ESA doses are withheld? Is there any difference between iron sucrose and iron dextran regarding transferrin saturation over time and response to ESA? Can we reduce ESA need by increasing dialysis dose in patients already receiving an adequate dialysis dose $(\mathrm{Kt} / \mathrm{V}>1.3)$ ? Still, it is fair to conclude that the ESA administration praxis where ESA doses are withheld does not reduce ESA demand. Instead, such practice could be associated with higher ESA requirements over time. On the basis of our results we recommend monthly rather than weekly hemoglobin measurements and a decrease in ESA dose rather than discontinuation of ESA treatment when an adjustment of hemoglobin treatment is considered necessary.

\section{Acknowledgments}

This work was supported by research grants from the Ingabritt and Arne Lundberg Research Foundation, the Knut and Alice Wallenberg Research Foundation, the Swedish Research council (9898 BH), and the Region Västra Götaland, Sweden.

\section{References}

1 Erslev AJ, Besarab A: Erythropoietin in the pathogenesis and treatment of the anemia of chronic renal failure. Kidney Int 1997;51:622-630.

2 Besarab A, Caro J, Jarrell BE, Francos G, Erslev AJ: Dynamics of erythropoiesis following renal transplantation. Kidney Int 1987;32:526-536.

3 Handelman GJ, Levin NW: Iron and anemia in human biology: a review of mechanisms. Heart Fail Rev 2008;13:393-404.

4 Elliott J, Mishler D, Agarwal R: Hyporesponsiveness to erythropoietin: causes and management. Adv Chronic Kidney Dis 2009;16:94-100.

5 KDOQI: KDOQI Clinical Practice Guideline and Clinical Practice Recommendations for anemia in chronic kidney disease: 2007 update of hemoglobin target. Am J Kidney Dis 2007;50:471-530.

6 USRDS: Annual Data Report. United States Renal Data System, 2010 (http://www.usrds.org/).

7 Locatelli F, Covic A, Eckardt KU, Wiecek A, Vanholder R: Anaemia management in patients with chronic kidney disease: a position statement by the Anaemia Working Group of European Renal Best Practice (ERBP). Nephrol Dial Transplant 2009;24:348-354.

8 Rice L, Alfrey CP, Driscoll T, Whitley CE, Hachey DL, Suki W: Neocytolysis contributes to the anemia of renal disease. Am J Kidney Dis 1999;33:59-62.

9 Koury MJ, Bondurant MC: Erythropoietin retards DNA breakdown and prevents programmed death in erythroid progenitor cells. Science 1990;248:378-381. 


\begin{tabular}{|c|c|}
\hline Nephron Extra 2011;1:45-54 & \\
\hline $\begin{array}{l}\text { DOI: 10.1159/000329889 } \\
\text { Published online: August 19, } 2011\end{array}$ & $\begin{array}{l}\text { (c) } 2011 \text { S. Karger AG, Basel } \\
\text { www.karger.com/nne }\end{array}$ \\
\hline
\end{tabular}

10 Daugirdas JT: Simplified equations for monitoring Kt/V, PCRn, eKt/V, and ePCRn. Adv Ren Replace Ther 1995;2:295-304.

11 KDOQI NKF: KDOQI Clinical Practice Guidelines and Clinical Practice Recommendations for Anemia in Chronic Kidney Disease. Am J Kidney Dis 2006;47:S111-S145.

12 Bellizzi V, Minutolo R, Terracciano V, Iodice C, Giannattasio P, De Nicola L, et al: Influence of the cyclic variation of hydration status on hemoglobin levels in hemodialysis patients. Am J Kidney Dis 2002;40:549-555.

13 Eschbach JW, Egrie JC, Downing MR, Browne JK, Adamson JW: Correction of the anemia of endstage renal disease with recombinant human erythropoietin. Results of a combined phase I and II clinical trial. N Engl J Med 1987;316:73-78.

14 Eschbach JW, Abdulhadi MH, Browne JK, Delano BG, Downing MR, Egrie JC, et al: Recombinant human erythropoietin in anemic patients with end-stage renal disease. Results of a phase III multicenter clinical trial. Ann Intern Med 1989;111:992-1000.

15 Fishbane S, Berns JS: Hemoglobin cycling in hemodialysis patients treated with recombinant human erythropoietin. Kidney Int 2005;68:1337-1343.

16 Beshara S, Barany P, Gutierrez A, Wikstrom B: Varying intervals of subcutaneous epoetin alfa in hemodialysis patients. J Nephrol 2004;17:525-530.

17 Jacobs C, Frei D, Perkins AC: Results of the European Survey on Anaemia Management 2003 (ESAM 2003): current status of anaemia management in dialysis patients, factors affecting epoetin dosage and changes in anaemia management over the last 5 years. Nephrol Dial Transplant 2005;20(suppl 3):iii3-iii24.

18 Barany P, Divino Filho JC, Bergstrom J: High C-reactive protein is a strong predictor of resistance to erythropoietin in hemodialysis patients. Am J Kidney Dis 1997;29:565-568.

19 Gunnell J, Yeun JY, Depner TA, Kaysen GA: Acute-phase response predicts erythropoietin resistance in hemodialysis and peritoneal dialysis patients. Am J Kidney Dis 1999;33:63-72.

20 Eschbach JW: Iron requirements in erythropoietin therapy. Best Pract Res Clin Haematol 2005;18: 347-361.

21 Kalantar-Zadeh K, McAllister CJ, Lehn RS, Lee GH, Nissenson AR, Kopple JD: Effect of malnutrition-inflammation complex syndrome on EPO hyporesponsiveness in maintenance hemodialysis patients. Am J Kidney Dis 2003;42:761-773.

22 Movilli E, Cancarini GC, Zani R, Camerini C, Sandrini M, Maiorca R: Adequacy of dialysis reduces the doses of recombinant erythropoietin independently from the use of biocompatible membranes in haemodialysis patients. Nephrol Dial Transplant 2001;16:111-114.

23 Danielson BG: Structure, chemistry, and pharmacokinetics of intravenous iron agents. J Am Soc Nephrol 2004;15(suppl 2):S93-S98.

24 Agarwal R, Davis JL, Smith L: Serum albumin is strongly associated with erythropoietin sensitivity in hemodialysis patients. Clin J Am Soc Nephrol 2008;3:98-104.

25 Gabay C, Kushner I: Acute-phase proteins and other systemic responses to inflammation. N Engl J Med 1999;340:448-454.

26 Qureshi AR, Alvestrand A, Danielsson A, Divino-Filho JC, Gutierrez A, Lindholm B, et al: Factors predicting malnutrition in hemodialysis patients: a cross-sectional study. Kidney Int 1998;53:773782.

27 Gaweda AE, Goldsmith LJ, Brier ME, Aronoff GR: Iron, inflammation, dialysis adequacy, nutritional status, and hyperparathyroidism modify erythropoietic response. Clin J Am Soc Nephrol 2010;5: 576-581.

28 Movilli E, Cancarini GC, Vizzardi V, Camerini C, Brunori G, Cassamali S, et al: Epoetin requirement does not depend on dialysis dose when $\mathrm{Kt} / \mathrm{N}>1.33$ in patients on regular dialysis treatment with cellulosic membranes and adequate iron stores. J Nephrol 2003;16:546-551.

29 Alfrey CP, Rice L, Udden MM, Driscoll TB: Neocytolysis: physiological down-regulator of red-cell mass. Lancet 1997;349:1389-1390.

30 Kelley LL, Green WF, Hicks GG, Bondurant MC, Koury MJ, Ruley HE: Apoptosis in erythroid progenitors deprived of erythropoietin occurs during the G1 and S phases of the cell cycle without growth arrest or stabilization of wild-type p53. Mol Cell Biol 1994;14:4183-4192.

31 Koury MJ, Bondurant MC: Maintenance by erythropoietin of viability and maturation of murine erythroid precursor cells. J Cell Physiol 1988;137:65-74. 